\title{
Juventude, trabalho e escola em territórios de precaridade social
}

\section{Luciana Pedrosa Marcassa* Soraya Franzoni Conde ${ }^{* *}$}

\section{Resumo}

Este artigo aborda a relação entre os jovens, o trabalho e a escola a partir dos dados de uma pesquisa sobre juventude e escolarização desenvolvida entre 2014 e 2016, em 10 escolas públicas localizadas nas imediações dos territórios do maciço do Morro da Cruz (Florianópolis, SC), região geopoliticamente segregada e periférica, embora situada no centro da cidade. Os dados são recolhidos por meio de estudos bibliográficos, análise de documentos, aplicação de questionários e grupos focais. As análises produzidas até agora evidenciam que o trabalho é central na vida dos jovens pesquisados tanto por fortalecer a relação com a escola, tendo em vista as projeções profissionais e de vida, quanto por, dialeticamente, competir com tempo de estudos fora do espaço escolar e ser um elemento determinante da fragilidade e do afastamento dos estudos.

Palavras-chave: Juventude. Trabalho. Escola. Maciço do Morro da Cruz.

\footnotetext{
* Doutora em Educação pela Universidade de Campinas (UNICAMP). Professora do Departamento de Metodologia de Ensino da Universidade Federal de Santa Catarina (UFSC).

** Doutora em Educação pela Universidade Federal de Santa Catarina (UFSC). Professora do Departamento de Estudos Especializados em Educação da Universidade Federal de Santa Catarina (UFSC).
} 


\section{Apresentação}

Este texto faz parte de uma pesquisa que investigou a relação dos jovens das periferias urbanas de Florianópolis com a escola, tendo em vista conhecer o que mantém e o que afasta a juventude da escola, considerando as múltiplas determinações e contradições que permeiam este processo, por exemplo, os diferentes sentidos atribuídos à escola pelos alunos, as condições socioeconômicas em que vivem, os motivos que geram a evasão escolar, a presença do trabalho na vida dos estudantes, suas expectativas de futuro e as atividades e interesses dos jovens para além da escola.

Trata-se de uma pesquisa qualitativa, exploratória e descritiva, que se utiliza de questionários aplicados com estudantes, de entrevistas com docentes, estudantes e gestores, de grupos focais e de análise de documentos, tendo como referencial teórico-metodológico o materialismo históricodialético. A pesquisa tem como foco os jovens estudantes, especialmente os do Ensino Médio, de 10 escolas públicas ${ }^{1}$ localizadas nos territórios do maciço do Morro da Cruz em Florianópolis/SC, região geopoliticamente segregada e periférica, embora situada no centro da cidade. Participam da pesquisa pesquisadores/docentes universitários, doutorandos, mestrandos, graduandos e professores da rede estadual de ensino. Além disso, foi realizado um seminário de socialização e discussão dos dados preliminares da pesquisa com a participação das escolas envolvidas.

O maciço do Morro da Cruz (MMC), território em que estão concentrados, especialmente, crianças e jovens atendidos pelas escolas públicas investigadas pela pesquisa, está situado na porção central da cidade de Florianópolis, mas não integra o cenário paradisíaco da "Ilha da Magia", amplamente divulgado na mídia. Composto por aproximadamente dezoito comunidades, sua população vive em habitações precárias e ainda sofre pela ausência de espaços de lazer e de serviços públicos adequados. Não há consenso em relação ao número de moradores das comunidades, mas as lideranças comunitárias estimam que existam cerca de trinta mil pessoas residindo nos morros da região, o que equivale a quase $8 \%$ da população absoluta da capital.

Compreendemos território conforme Milton Santos (2011, p. 96), ou seja: “o chão e mais a população, isto é, uma identidade, o fato e o sentimento de pertencer àquilo que nos pertence. O território é a base do trabalho, da residência, das trocas materiais e espirituais e da vida, sobre os quais se influi". Dessa maneira, quando falamos de território, supomos o território usado, ocupado, utilizado pela população. Em nosso caso, “território de precariedade" é o espaço social ocupado por famílias de 
baixa renda, que vivem em condições precárias de moradia e trabalho, submetidos à tirania do mercado e à diminuição da esfera pública no atendimento às suas necessidades básicas, portanto local onde se verifica o enfraquecimento das relações entre os sujeitos coletivos na medida mesma do aumento do poder e do controle do crime organizado e do narcotráfico. A locução adjetiva "de precariedade" só pode ser entendida se somada ao substantivo "social"; assim, o termo mais adequado seria território de precariedade social, pois explica o fato de o maciço do Morro da Cruz ser uma das regiões mais empobrecidas, vulneráveis ${ }^{2}$ e violentas da cidade de Florianópolis. A constituição do MMC denota o processo de expansão das periferias urbanas, iniciado nos anos 1970, e o crescimento da favelização, que resulta da produção e intensificação das desigualdades sociais articuladas à expansão do capitalismo no Brasil. O território de precariedade social, portanto, é cenário geopolítico de articulação entre o local e o global e faz parte do processo de desenvolvimento desigual e combinado do capitalismo contemporâneo, que introduz e reproduz relações as mais avançadas e modernas, como também as mais arcaicas, todas necessárias e compatibilizadas à acumulação do capital. De acordo com Francisco de Oliveira (1988, p. 32-34):

De fato o processo real mostra uma simbiose e uma organicidade, uma unidade de contrários, em que o chamado "moderno" cresce e se alimenta da existência do "atrasado" [...] tal postulação esquece que o subdesenvolvimento é precisamente uma produção da expansão do capitalismo [...] A ênfase no aspecto da dependência do subdesenvolvimento com relação ao desenvolvido, deixa de abordar aspectos internos da estrutura de dominação. O problema se torna como que uma oposição entre nações, esquecendo que o problema do desenvolvimento se relaciona à oposição entre classes sociais internas $[\ldots]$.

As mediações criadas no/pelo território de precariedade social afetam diretamente a condição juvenil e a experiência de viver a juventude. Nesses territórios, segundo Denise Cordeiro (2009), normalmente impera

[...] a mundialização do capital, a globalização e a colonização da cultura pela via da indústria cultural, a influência dos meios de comunicação de massa, o poder autoritário da tecnologia, o tom profético neoliberal que dá ênfase ao Estado eficiente e produtivo a partir da lógica empresarial, à supremacia do individualismo ao empobrecimento das populações. (CORDEIRO, 2009, p. 53).

Assim, a juventude pobre dos territórios de precariedade social não foge dos processos de controle, de contenção e de conformação de suas práticas, comportamentos e ideias, de seus modos de viver e conviver na e com a pobreza. 
Por outro lado, o aumento das oportunidades educacionais, do prolongamento da escolarização média, das políticas de acesso e permanência nos estabelecimentos de ensino (na Educação Básica e no Ensino Superior), das políticas públicas pensadas e implementadas para a juventude brasileira nos últimos 30 anos, bem como a emergência de movimentos sociais, no campo e na cidade, liderados por jovens, revela as novas formas de expressão da juventude brasileira, suas demandas e modos de inserção na totalidade social, incluindo as lutas por melhores condições de vida, trabalho e formação. A juventude não é, portanto, somente objeto de controle político e ideológico, é também sujeito de muitas lutas e conquistas de direitos, por exemplo, à moradia, à urbanização, ao transporte, à educação, à liberdade de expressão, à participação social e política. Assim, trata-se de perceber não apenas múltiplas determinações que atuam sobre as formas de ser e viver da juventude pobre brasileira mas também seus movimentos de resistência e luta a essas determinações e condicionamentos.

Vale dizer que, quando falamos em "juventude", concebemo-la como categoria social que se caracteriza, ao mesmo tempo, pela heterogeneidade e pelo agrupamento, pela diversidade e pela semelhança, portanto marcada por determinações de classe, gênero, etnia e também clivada por diferenças produzidas pelas condições educacionais e culturais, pelo local de moradia e pela relação que estabelece com outras gerações, em especial com o mundo adulto e sua entrada nele (MARCASSA, 2017, p. 14). Por isso, é importante compreender as experiências concretas em meio as quais a juventude se produz, articulando expectativas, o ambiente cultural, trajetórias, modos de pensar e agir com as condições materiais e concretas em que esses jovens estão inseridos. Como diz Maria Alice Foracchi (1977, p. 303) no clássico estudo sobre O estudante e a transformação da sociedade brasileira, "menos do que uma etapa cronológica da vida, menos do que uma potencialidade rebelde e inconformada, a juventude sintetiza uma forma possível de pronunciar-se diante do processo histórico e de constituí-lo, engajando-se".

A partir das premissas acima explicitadas, este texto explora as contradições vividas pelos jovens estudantes das escolas do MMC diante da encruzilhada do trabalho e do estudo, explorando os aspectos que fortalecem a escolarização e a elaboração de projetos superadores de suas próprias condições de classe e de vida, bem como aqueles que fragilizam a relação do jovem com a escola, atravancando seu percurso escolar, frustrando desejos e expectativas, levando, assim, ao abandono e à sujeição dos jovens estudantes-trabalhadores, precocemente, às condições de vida e trabalho próprias de sua classe. 


\section{Os jovens e suas necessidades concretas}

"[...] muitas vezes a gente não tem nem escolha, a gente tem que trabalhar porque a gente precisa daquele dinheiro no final do mês e aí eles exploram da gente, porque sabem que a gente vai fazer aquilo porque a gente precisa daquilo. Isso que é o mais difícil! Tem gente que está trabalhando aqui porque quer o dinheiro no bolso, mas tem gente que precisa daquele dinheiro, porque tem um destino já ideal para aquele dinheiro, ai eles obrigam a gente e nós temos que fazer aquilo sem falar: não, eu não fui contratado para fazer isso!" (Grupo Focal 3EM matutino, Escola HS, 2014).

Os sujeitos da pesquisa são estudantes dos anos finais do Ensino Fundamental $\left(7^{\mathbf{o}}\right.$ e $\left.8^{\mathbf{o}} \operatorname{anos}^{3}\right)$ e principalmente do Ensino Médio $\left(1^{\circ}, 2^{\circ}\right.$ e $3^{\circ}$ anos) que frequentam as escolas mencionadas nos três períodos, matutino, vespertino e noturno, totalizando 1.181 estudantes.

A partir dos dados coletados, podemos afirmar que o trabalho (formal ou informal, temporário, parcializado, periódico ou na situação de estágio) é uma realidade para a maioria desses sujeitos, já que as escolas pesquisadas concentram os filhos de frações empobrecidas da classe trabalhadora, os quais necessitam trabalhar para sobreviver. De acordo com o questionário aplicado aos estudantes, 69,2\% dos respondentes estudam e trabalham (ou pretendem/precisam trabalhar), 33,7\% começaram a trabalhar antes dos 16 anos de idade, 21,9\% entraram no mercado de trabalho durante a fase dos 14 aos 16 anos (idade do trabalho como forma de aprendizagem) e 16,3\% iniciaram a atividade laborativa com mais de 16 anos, o que revela a existência de trabalho precoce e trabalho infantil entre esta população. Embora exista um número significativo de estudantes que nunca trabalhou (47,8\%), é espantoso perceber que quase $50 \%$ deles já iniciaram suas vidas como trabalhadores.

Gráfico 1 - Idade com que começou a trabalhar

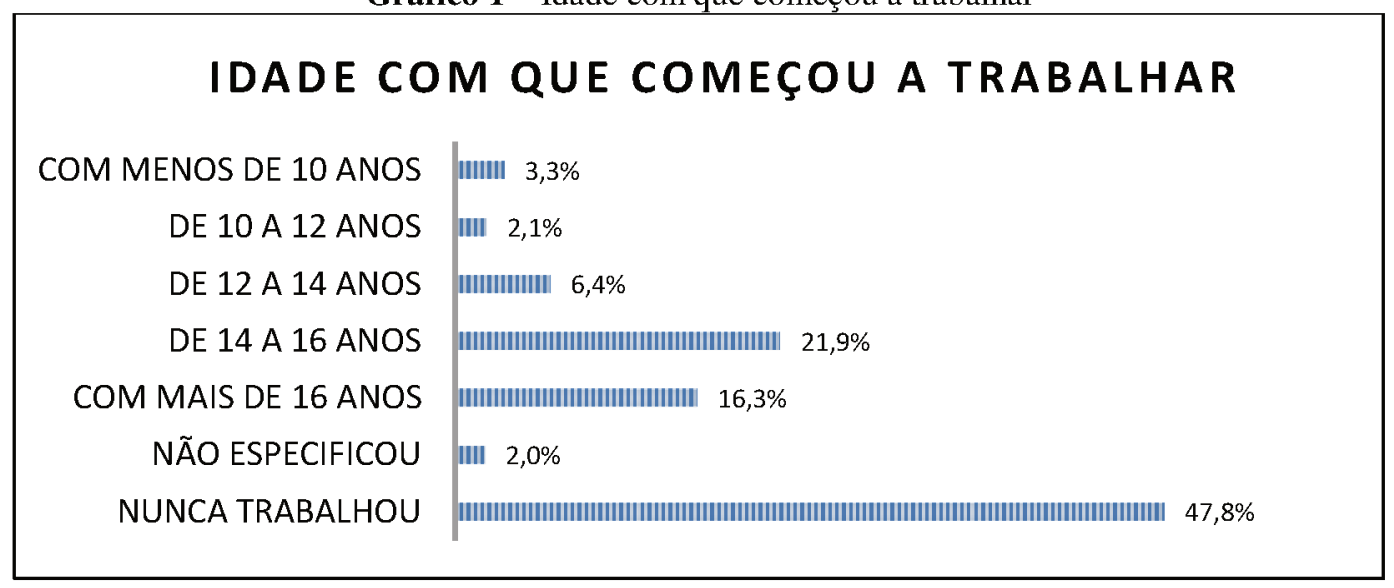

Fonte: Elaborado pelas autoras. 
O perfil dos jovens que frequentam as escolas da pesquisa é o estudante-trabalhador: membro de família da classe trabalhadora (51\% das famílias têm renda de até 4 salários mínimos), 66\% vive com os pais, os quais possuem escolaridade média ou baixa, ou seja, não chegaram a concluir o Ensino Médio, morador da periferia da cidade, principalmente dos territórios do MMC e bairros adjacentes, que se insere precocemente no mercado de trabalho, atua com grande incidência na informalidade ou em condição de estagiário, em situações precárias e em funções simples (lavador de carro, assistente de almoxarifado, assistente de escritório, em restaurantes, pizzarias, postos de combustível, redes de fast food, telemarketing etc.), recebe baixa remuneração e exerce sua atividade em longa e extenuante jornada de trabalho, algumas vezes igual ou superior à quarenta horas semanais.

No que diz respeito ao trabalho em particular, percebemos que ele faz parte do cotidiano dos jovens que estudam de dia e de noite, ainda que neste último seja mais frequente. Encontramos jovens que estudam pela manhã e trabalham à tarde, à noite ou nos finais de semana. Alguns trabalham como estagiários, quatro horas por dia ou mais. Diante desse dado, percebemos que a escolha ou procura por um determinado turno escolar não tem ligação direta com o ingresso ou não no trabalho, já que, em algumas escolas, que atendem alunos de menor renda familiar, o trabalho está presente na vida dos estudantes de diferentes turnos. Em outras escolas, nas quais foi verificada renda mensal familiar um pouco maior, o trabalho não é uma constante na vida dos estudantes, especialmente entre os que estudam de dia, como no caso dos jovens que frequentam o Ensino Médio Inovador (EMI ${ }^{4}$, os quais permanecem o dia todo na escola. Por outro lado, nos grupos focais realizados nas duas escolas com EMI, os jovens revelaram trabalhar nos finais de semana e/ou fazendo "bicos", o que evidencia que frequentar uma instituição educativa durante período integral não garante que o jovem não trabalhe. Assim, o que parece mais determinante, neste caso, é a condição socioeconômica do jovem e de sua família, ou seja, a necessidade de incrementar a renda doméstica, ou de o jovem poder ter sua própria renda, ou ainda garantir sua subsistência. De qualquer forma, a presença marcante do trabalho na rotina dos estudantes compete com o tempo destinado aos estudos fora da escola.

Gráfico 2 - Aspectos que atrapalham os estudos fora da escola 


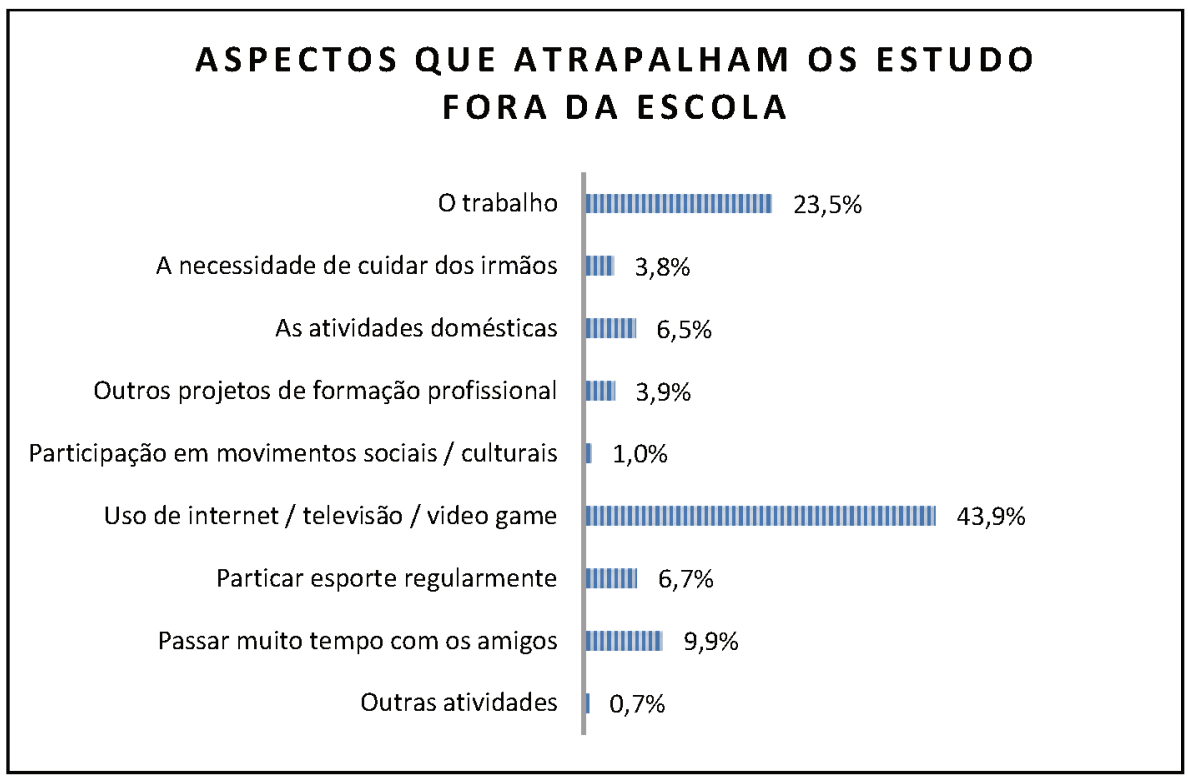

Fonte: Elaborado pelas autoras.

Observamos, portanto, por meio dos questionários e grupos focais, uma clara relação entre renda familiar e trabalho dos jovens. As escolas em que as famílias têm uma renda mais baixa são as que contam com maior incidência de estudantes que trabalham e também que começaram a trabalhar mais cedo. Enquanto isso, nas escolas com famílias de renda levemente superior, há menor incidência de trabalho entre os estudantes ou estes trabalham para cobrir suas próprias despesas, e não para prover subsistência da família. De um modo geral, considerando a amostra da pesquisa, a renda familiar é baixa em todas as escolas: em 9\% delas, as famílias recebem até um salário mínimo; $22 \%$ têm renda de um a dois salários mínimos; 20\%, de 2 a 4 salários mínimos, o que explica o fato de a maioria dos estudantes trabalhar ou precisar trabalhar, ainda que muitos deles não permaneçam ocupados durante um período longo ou regular de tempo.

A grande maioria aqui é pobre, classe social baixa [...]. E eu não tenho dinheiro, se não trabalhar, minha mãe não vai me dar, ninguém vai me dar, então eu tenho que me sustentar e tenho que fazer as coisas por mim. Porque, se não, ninguém vai fazer. (Grupo Focal, 1, 2 e 3 EM noturno - Escola LM, 2014).

A incidência de trabalho entre os jovens também está relacionada à baixa escolaridade dos pais. Na amostra geral das escolas, $19 \%$ dos pais e $20 \%$ das mães têm ensino fundamental incompleto; $5 \%$ dos pais e 5\% das mães são analfabetos e há um número grande de jovens que não sabem ou não responderem a questão ( $21 \%$ em relação aos pais e $14 \%$ em relação às mães). 
Portanto, considerando a especificidade dos jovens destas escolas, observamos uma relação entre o trabalho precoce, a renda familiar baixa, os trabalhos simples e precários com baixos salários e longa jornada de trabalho e a baixa escolaridade dos pais ${ }^{5}$. No grupo focal realizado com estudantes da Educação de Jovens e Adultos da Escola SS, os participantes revelaram ter dois vínculos de trabalho, devido aos baixos salários ${ }^{6}$ :

[...] estava trabalhando em dois serviços e estudava. Daí eu optei, ou trabalhar ou estudar, os três não dava para fazer. Aí parei de estudar para trabalhar. Eu optei por trabalhar, porque tinha a mãe e tinha dois irmãos pequenos em casa. Aí eu saí para poder ajudar a minha mãe, porque só a minha mãe sozinha não dava de sustentar eu e mais meus dois irmãos pequenos. (Grupo Focal EJA, segundo segmento noturno, Escola SS, 2014).

Percebemos, assim, que o trabalho desempenhado pelos jovens estudantes-trabalhadores, além de ser uma necessidade decorrente das condições socioeconômicas em que vivem é, principalmente, do tipo trabalho simples ${ }^{7}$, irregular, inseguro, informal, mal remunerado, precário, que atende tão somente às necessidades de produção e acumulação do capital, segundo a análise de Marx, e não às necessidades dos trabalhadores. Estes, por sua vez, recebem salários muito baixos e, portanto, precisam vincular-se a mais de um tipo ou contrato de trabalho. Além disso, toda a família precisa trabalhar. Segundo o relato de jovens nos grupos focais, eles arcam com parte das despesas da casa (contas de luz, aluguel), bem como com despesas próprias (transporte, alimentação, roupas, aparelhos de celular, despesas com lazer e outros). Há ainda o caso de jovens (particularmente os que migraram de outros estados) que moram com amigos ou parentes ou com namorados/companheiros, sem o apoio da família; estes precisam trabalhar para arcar com todas as suas despesas.

Portanto, esses jovens que começam a trabalhar muito cedo, em longas jornadas diárias, com salários baixos, ou seja, que trabalham por necessidades econômicas e de subsistência, têm enfrentado problemas com a continuidade dos estudos, uma vez que o trabalho concorre diretamente com as obrigações escolares naquele tempo que deveria ser dedicado aos estudos. A consequência disso se vê na ausência constante das aulas, na falta de organização do material escolar, na não realização de tarefas e na falta de leitura e estudo, situações que conduzem os jovens ao abandono progressivo, geram reprovação e levam muitos estudantes a desistir da escola, temporária ou mesmo definitivamente.

Mas, apesar de as condições socioeconômicas determinarem a necessidade do trabalho e do trabalho atrapalhar os estudos, na percepção dos jovens pesquisados, há outros fatores que os levam a 
se inserir no mercado de trabalho, os mesmos que justificam a preferência pelo turno matutino ou noturno, uma vez que assim conseguem, supostamente, conciliar trabalho e estudo:

[...] é só porque eu tô conseguindo ajudar os meus pais, porque atualmente eles estão desempregados, aí eu tô conseguido sustentar eles e me sustentar ao mesmo tempo. (Grupo Focal 3EM matutino, Escola HS, 2014).

Eu trabalho numa lanchonete, sou caixa da lanchonete. E eu escolhi trabalhar pra conseguir uma independência, pra não ter que ficar dependendo dos meus pais, e também pra ajudar. (Grupo Focal 3EM matutino, Escola JC, 2014).

Eu trabalho tanto para adquirir um pouco de experiência, que eu não tinha nenhum tipo de experiência e para ajudar também em casa, essas coisas assim. (Grupo focal 3EM matutino, Escola HS, 2014).

É um tempo que eu poderia estar trabalhando, ganhando meu dinheiro, eu podia estar aprendendo com coisas novas, conhecendo pessoas. Aí eu corri atrás, corri atrás, corri atrás. (Depoimento estudante do 3EM matutino - Escola PA, 2014).

Como vimos, há muitos outros sentidos atribuídos ao trabalho pelos jovens, tais como: “ajudar economicamente a família", "ter independência financeira", “adquirir experiência”, "aprender coisas novas e conhecer pessoas", entre outras motivações. Chama a nossa atenção o fato de eles conceberem o trabalho como uma "escolha pessoal", e não como uma necessidade, aceitando e se acomodando diante da difícil tarefa de conciliar escola e trabalho. Com isso, incorporam as formas ideológicas em que os determinantes da necessidade de trabalhar desde cedo aparecem como uma escolha individual, tal como afirma a estudante: "Eu trabalho numa padaria, desde os 17, tô trabalhando porque eu quero mesmo, e eu sou repositora, há uns 3 meses, e pretendo continuar" (Grupo Focal do 3EM matutino, Escola JC, 2014).

Ora, essa ideologia, que difunde valores e práticas como o individualismo, a meritocracia e a autorresponsabilização, tem uma base material muito clara: as relações produtivas no contexto da acumulação flexível. O processo de reestruturação produtiva impôs sobre a organização do trabalho uma nova dinâmica, marcada, sobremaneira, pela ideia de flexibilização. As mudanças mais significativas no campo da produção estão relacionadas às inovações tecnológicas, organizacionais e sociometabólicas (ALVES, 2012). Essas inovações aumentam a produtividade do capital, seja pela implementação de novas tecnologias que comprimem o trabalho necessário e aumentam o trabalho excedente, acarretando mais trabalho para uns e desemprego para outros, seja pela tentativa de captura da subjetividade do trabalhador, ou mesmo pelos esforços contínuos de explorar ao máximo todas as 
suas capacidades físicas e mentais (ALVES, 2012). As inovações sociometabólicas foram e são essenciais para a efetivação das inovações organizacionais proposta pelo modelo toyotista, já que criaram um metabolismo que rompeu com o nexo psicofísico do taylorismo-fordismo e em seu lugar estabeleceu um novo nexo psicofísico capaz de capturar a subjetividade do trabalhador.

Por outro lado, os jovens são afetados pela crise atual do capital que, na particularidade do Brasil, aparece como crise econômica e do emprego formal ${ }^{8}$. Segundo dados do Departamento Intersindical de Estatística e Estudos Socioeconômicos (DIEESE, 2016, p. 4),

[...] entre os jovens, que correspondem a 43,2\% no total de ocupados no início de 2016, o crescimento mais expressivo ocorreu para os que tinham idade entre 14 e 17 anos: aumento de $80,5 \%$ da taxa de desocupação, que passou a 37,9\%. Entre os jovens de 18 a 24 anos, a taxa de desocupação cresceu $70,9 \%$, atingindo $24,1 \%$ no primeiro trimestre de 2016.

Assim, se o trabalho é uma realidade para parcela significativa dos nossos jovens, a falta dele ou as consequências da crise do capital também o são, e isso reverbera sobre as expectativas que os jovens têm em relação à escola, aos estudos e aos projetos profissionais.

Com o aumento do desemprego, a formação e a escolaridade têm se tornado requisitos fundamentais à conquista de um lugar no concorrido mercado de trabalho. A "certificação" se transformou em condição de empregabilidade, mesmo quando a função a ser ocupada não necessita de todas as qualificações que o candidato selecionado possui. É parte do jogo ideológico do sistema capitalista ocultar o problema estrutural e convertê-lo em exigência de qualificação do trabalhador, como se a oferta de emprego derivasse da formação do sujeito, e não da demanda produtiva. Quanto maior o número de desempregados, maior é o número de exigências que o empregador pode fazer, mesmo para postos de trabalho considerados simples.

Se a expansão da escola pública correspondeu, historicamente, às necessidades de formação para o trabalho, segundo as necessidades capitalistas de cada contexto, por outro lado, a escola pública se tornou um direito conquistado duramente pela classe trabalhadora, sendo hoje obrigatória no Brasil dos 4 aos 17 anos. O Ensino Médio, por sua vez, como campo de preocupações e de disputa hegemônica (haja vista a última reforma que alterou a Lei de Diretrizes e Bases da Educação Nacional, Lei $n^{\circ}$ 9.394, de 20 de dezembro de 1996, e criou o Novo Ensino Médio pela Medida Provisória $n^{\circ}$ 746, de 29 de setembro de 2006) permanece ainda hoje como uma etapa da escolarização cheia de desafios, dilemas e encruzilhadas, tanto do ponto de vista dos jovens como do ponto de vista dos docentes, gestores e formuladores de políticas públicas. Segundo dados do último Censo Escolar (IBGE, 2016), 
há 2,8 milhões de pessoas entre 4 a 17 anos que não frequentam a escola no Brasil, entre as quais pouco mais de 1,7 milhões são adolescentes e jovens, ou seja, encontram-se na faixa etária dos 14 aos 17 anos. Diante deste quadro, cabe interrogar: que motivos levam os jovens a abandonar a escola e mesmo os elementos que a escola oferece ou pode oferecer para fortalecer a presença e permanência do jovem no curso da escolarização? Em nossa hipótese, essas e outras questões sobre a relação do jovem com a escola não podem ser corretamente respondidas se não considerarmos o lugar do trabalho na vida da juventude pobre brasileira.

Em nossa pesquisa, ao buscar compreender os sentidos atribuídos à escola e ao processo de escolarização na sua relação com o trabalho, interrogamos os jovens sobre os motivos pelos quais vão à escola. Conforme os dados da pesquisa, 49\% dos jovens buscam a escola "para adquirir conhecimentos"; e outros 31,3\%, "para melhorar seu futuro e de sua família". Isto indica que os jovens atribuem à escola o sentido de realização pessoal, projeção econômica e ascensão social, ainda que a escola não seja capaz de realizar essa integração com o trabalho, dado o quadro de desemprego estrutural existente hoje no Brasil. Por outro lado, é fato que mais da metade dos jovens da pesquisa (69\%) já trabalha ou precisa trabalhar em virtude de suas condições econômicas. É assim que, na relação com o trabalho, a escola perde o sentido de "adquirir conhecimentos", já que não permite a inserção do jovem no trabalho como atividade realizadora, mas, ao contrário, obriga-o a aceitar qualquer oportunidade de emprego que lhe garanta subsistência, assumindo o significado de "certificação" necessária ao ingresso no mundo produtivo, como uma credencial para o acesso ao emprego e à renda.

Não é o ensino da escola, em si, que vai nos levar para frente, mas sim para terminar o terceiro ano, está escrito ali, terceiro ano, entendeu? É o papel que vale mais, não vale o conhecimento, o que vale é o papel. (Grupo Focal, 3 EM noturno, Escola SH, 2015).

Esse fenômeno da transformação da escola em mera agência de certificação é revelador de dois processos simultâneos e contraditórios. Um deles deflagra o caráter da escola, que define a formação escolar pelas relações por meio das quais a escola se realiza, ou seja, historicamente, a escola cumpre uma função de controle e manutenção da ordem de dominação. Como afirma Algebaile (2016):

[...] a escola moderna não nasce como direito, mas como recurso estratégico de um Estado em constituição que, para firmar-se como instituição política em uma nova escala (a escala dos Estados nacionais) e segundo novas formas de legitimação do exercício de poder (fundamentais em pressupostos racionais legais) precisa 
desenvolver instituições que realizem com efetividade novas e mais complexas funções de dominação e controle da população e do território. (ALGEBAILE, 2016, p. 56-57).

Por outro lado, é fruto da crise do capital que produz a ruptura da linha de continuidade entre formação escolar e mercado de trabalho - possível somente em contextos de pleno emprego - e inviabiliza as possibilidades de mobilidade social ascendente ambicionadas pelos estudantes. De acordo com Gentili (1999), este segundo processo indica o fim da promessa integradora da escola e sua consequente substituição pela promessa de empregabilidade, que se torna uma consequência necessária das contradições do modo de produção capitalista, as quais pressionam os jovens a obter sempre novas credenciais de acesso ao mercado de trabalho, em "uma busca cada vez mais forte de novas oportunidades, configurando uma demanda endógena de escolaridade” (SPÓSITO, 2004, p. 79).

Em virtude dessa busca incessante das condições de empregabilidade requeridas pelo mercado, temos uma realidade educacional diversa no Brasil: os jovens da pesquisa já superaram o grau de escolaridade dos pais, mas isso não implica maior domínio de conhecimentos e nem maior renda. Ainda assim, o vínculo com a escola, mesmo frágil, é estabelecido em razão de necessidades concretas e das projeções de futuro que jovens trabalhadores elaboram em seus percursos de formação, muitas vezes interrompidos, dentro e fora da escola:

Porque eu sei que lá na frente vou me arrepender [se não estudar]. Eu vou querer ter o que os outros têm, eu vou querer ter carro, casa só para mim e aí eu sei que não ia dar. (Grupo Focal, segundo segmento EJA, matutino, Escola SS, 2015).

Preciso ser alguém na vida, e aí, quando crescer, vou estar sossegado e conseguir um emprego bom. (Grupo Focal, segundo segmento EJA, matutino, Escola SS, 2015).

Se por um lado os estudantes buscam a escola por acreditar que ela lhes oferece credenciais de acesso ao emprego ("preciso ser alguém na vida"), as quais estão intimamente relacionadas com os benefícios que o trabalho pode lhes trazer (subsistência, estabilidade, consumo, o "carro", a "casa", etc.), por outro lado, a escola, nas condições precárias em que se encontra, não corresponde aos desejos e expectativas dos jovens, uma vez que ela, ao invés de ampliar horizontes, universalizar condições de permanência e sucesso alicerçadas em padrões socialmente referenciados de qualidade pedagógica, promove uma conformação social pela via da dualidade de novo tipo, em que a quantidade e variedade das ofertas de formação, as condições de permanência, o acesso ao conhecimento e a obtenção da certificação não significam oferta ampla, “mas sim pulverizada, desigual, regular, instável [...] cujos sentidos verdadeiros só são apreensíveis se levarmos em conta o efeito de conjunto dessa variedade de 
ações instáveis e orgânicas à lógica da forte fragmentação do trabalho e do imprescindível controle social” (RUMMERT; ALGEBAILE; VENTURA, 2012, p. 44).

Percebemos, dessa forma, uma enorme contradição entre o que os jovens desejam e esperam da escola e o que a escola pública tem lhes proporcionado em termos de formação e projeção de futuro. Os conhecimentos assumem um caráter de certificação e têm relação direta com a inserção dos jovens no mercado de trabalho, mas este último tem demonstrado incapacidade de acolher a juventude escolarizada, a não ser como "exército de reserva", no trabalho informal, precário e simples.

\section{Os jovens, seus dilemas e encruzilhadas: entre o trabalho e a escola}

É bastante cansativo, a vida é corrida. Eu saio às 6 horas de casa e volto às 11 horas da noite, de segunda a sexta, é bem cansativo. Às vezes você pensa em desistir de trabalhar, mas você tem que pensar lá na frente. Só que não tem como desistir de trabalhar, porque eu sei que a minha mãe não tem condições de dar o que eu quero, $e$ você vê que você trabalhando, você consegue comprar o que você quer. (Grupo Focal, 3 EM noturno - Escola SH, 2015).

Quando questionados acerca dos pontos negativos decorrentes da necessidade de combinar estudo e trabalho, os jovens indicam estar numa encruzilhada, pois, ao mesmo tempo em que percebem e são cobrados para que obtenham "certificação", a condição de estudante-trabalhador gera cansaço, estresse e acarreta falta de tempo para os estudos. Uma estudante da Escola PA afirma que a desvantagem de trabalhar é que "fica bem corrido, sim, né? Às vezes é cansativo também, então, essa parte é ruim". Assim, eles tentam, mas logo sentem as dificuldades de conciliar as duas atividades, o que resulta no excesso de faltas, diminuição do rendimento escolar, reprovação, abandono temporário, quase sempre seguido do retorno à escola em virtude das exigências do mercado de trabalho (muitas vezes retornam na modalidade EJA) e, consequentemente, desistência definitiva e incontornável.

Além disso, uma das implicações destacadas é que o excesso de trabalho fora da escola resulta na ausência do tempo livre. Como são adolescentes e jovens, desejam sair, namorar, dançar, conversar com os amigos da mesma idade, jogar bola, escutar música, entre outras coisas. Reclamam, portanto, que esse momento é comprometido, evidenciando que, para os filhos da classe trabalhadora, ser adolescente e jovem significa saltar da infância ao mundo trabalho.

Com isso, destacamos o dilema vivido pela juventude pobre: ao mesmo tempo em que buscam ampliar a escolaridade para se qualificar para o mercado de trabalho, a necessidade imediata de 
trabalhar resulta em cansaço e falta de tempo para os estudos e, por isso, os jovens acabam se distanciando e/ou desistindo da escola. Ainda para aqueles que persistem e conseguem avançar no percurso escolar, mesmo trabalhando, a combinação de estudo e trabalho faz com que se constituam "estudantes pela metade", pois sua condição de trabalhadores os impede de viver plenamente todas as dimensões da vida estudantil: atividades culturais, festas, manifestações, grêmios, movimentos estudantis, jogos desportivos, entre outros. Conforme verificamos no Grupo Focal realizado em 2014 com estudantes do 3EM matutino da Escola JC:

Eu até consegui dividir os dois um pouco [a escola e o trabalho], porque um foca mais numa coisa do que o outro. Então como eu tava conseguindo e lá tem bastante movimento, então, fico cansada, não tem como focar na escola aqui, pois já venho cansada e daqui a pouco tem que sair para trabalhar de novo, então, é sempre assim.

No caso da escola SS, na qual se realiza a EJA, mais de $50 \%$ dos estudantes disseram que o que mais atrapalha os estudos é o trabalho, porém este aparece apenas em terceiro lugar (com 12\%) como fator de evasão escolar. Neste caso, talvez o trabalho não figure em primeiro lugar como motivo de abandono porque os estudantes da EJA já desistiram da escola em outro momento e retornaram justamente pela percepção da importância dos estudos, seja por "certificação", seja por uma cobrança do mercado de trabalho que, hoje, exige, no mínimo, o Ensino Médio.

Observamos, em nossa pesquisa, portanto, tal como Maria Alice Foracchi (1977) já havia demonstrado, que o trabalho representa para o estudante a possibilidade efetiva de manter-se como estudante. Segundo a autora:

$\mathrm{O}$ trabalho proporciona ao jovem recursos materiais para preservar-se como pessoa e como condição social [...]. Mas, na medida em que é, basicamente, uma garantia para manutenção da condição de estudante, o trabalho só é socialmente possível como trabalho parcial [...]. O trabalho possui, desse modo, conteúdo emancipador provisório, indicado pela transitoriedade com que é encarada a necessidade elementar que atende (ter dinheiro para fazer o que quiser). Se o trabalho, como recurso social de emancipação, só pode ser um trabalho parcial, é admissível concluirmos desde já que a emancipação a ser obtida será, pelas mesmas razões, também parcial. (FORACCHI, 1977, p. 128).

Mas, por outro lado, o estudante que trabalha não pode impedir que sua atividade esteja cindida entre o emprego e o estudo, na medida em que um é condição do outro. Com isso, a aprendizagem, assim como o emprego, só pode ser parcial, tanto no que diz respeito ao aproveitamento quanto no tocante à experiência obtida, num ou noutro setor (FORACCHI, 1977). 
Dessa forma, fica claro que a relação do estudante-trabalhador com a escola é caracterizada por certa encruzilhada. Ao mesmo tempo em que o jovem busca alongar sua escolarização para conquistas profissionais e pessoais futuras, o trabalho concorre fortemente com os estudos. A necessidade de trabalhar enquanto condição de subsistência acaba por se configurar, na vida dos jovens, como algo que reduz sua possibilidade como estudante, na medida em que limita seu tempo para o estudo, muitas vezes prejudicando e interrompendo seu percurso escolar. Ao mesmo tempo, não o realiza como jovem, dado o caráter imediato e transitório com que é encarado.

\section{Considerações finais}

A relação entre os jovens, o trabalho e a escola é algo relevante no Brasil uma vez que cerca de 9,8\% (4,5 milhões) da população entre 5 e 18 anos trabalha (IBGE/PNAD, 2009). Entre os ocupados, $80 \%$ frequentam a instituição escolar, e a escolarização é sempre maior entre aqueles que não trabalham. À medida que a idade avança, há diminuição do tempo de dedicação aos estudos e aumento do tempo de trabalho, até que este passa a ocupar todo o tempo da jornada diária dos jovens. Entre os que permanecem estudando, o tempo de estudos vai sendo absorvido pelo trabalho, o descanso e o lazer, comprometendo a aprendizagem dos estudantes, que chegam cansados à escola após tantas tarefas, fato este também confirmado pelos dados de nossa pesquisa. Isso evidencia que, para a classe trabalhadora, a fase da juventude significa um salto direto para a vida adulta com inúmeras responsabilidades.

Os dados analisados corroboram a centralidade da categoria trabalho na vida dos jovens pesquisados. Mas, diante das contradições inerentes à sociedade capitalista, tal centralidade culmina numa encruzilhada. Se, por um lado, o trabalho determina as projeções profissionais e de vida dos jovens que frequentam a escola, por outro, dialeticamente, compete com o tempo de estudos fora do espaço escolar, gera cansaço e acaba se tornando um elemento determinante para o afastamento e/ou interrupção dos estudos entre estudantes trabalhadores.

\section{Notas}

${ }^{1}$ Aqui identificadas por siglas: PA, HT, HS, LM, GV, IEE, MLM, JC, SH, SS, sendo esta última responsável pela oferta de EJA - Educação de Jovens e Adultos. 
${ }^{2}$ Vulnerável aqui do ponto de vista ambiental, uma vez que se trata de aglomeração humana em morros e encostas, portanto área sensível aos eventos climáticos e suscetível aos efeitos do desmatamento e das ocupações irregulares e precárias.

${ }^{3}$ Quando a primeira etapa da pesquisa foi realizada (aplicação do questionário), as escolas estavam se adaptando ao Ensino Fundamental de 9 anos e, na ocasião, as novas turmas ainda não haviam chegado ao $9^{\circ}$ ano.

${ }^{4}$ Segundo o site do MEC, “O Programa Ensino Médio Inovador - ProEMI, instituído pela Portaria n 971 , de 9 de outubro de 2009, integra as ações do Plano de Desenvolvimento da Educação - PDE, como estratégia do Governo Federal para induzir a reestruturação dos currículos do Ensino Médio. O objetivo do ProEMI é apoiar e fortalecer o desenvolvimento de propostas curriculares inovadoras nas escolas de Ensino Médio, ampliando o tempo dos estudantes na escola e buscando garantir a formação integral com a inserção de atividades que tornem o currículo mais dinâmico, atendendo também às expectativas dos estudantes do Ensino Médio e às demandas da sociedade contemporânea." Disponível em: <http://portal.mec.gov.br/ensino-medio-inovador/apresentacao>. Para saber mais, cf. Nogara Junior (2015).O CORRETO AQUI É NOGARA JUNIOR

${ }^{5}$ Observamos as interconexões entre renda familiar, salário, condições de trabalho e escolaridade. Com isso, não queremos afirmar que o aumento da escolaridade resulte em aumento da renda familiar e menor trabalho precoce, como tem sido propalado de forma recorrente pela ideologia da empregabilidade ou do ciclo vicioso da pobreza.

${ }^{6}$ Os dados aqui apresentados sobre a relação do jovem com o trabalho, e deste com a renda familiar e a escolaridade dos pais já foram por nós discutidos com maior profundidade em outra oportunidade (VENDRAMINI, MARCASSA, TITTON, CONDE, 2017). REFERÊNCIA CORRETA E ACRESCIDA AO FINAL

${ }^{7}$ Sobre trabalho simples e qualificado, Marx (2008) evidencia como é ilusória a distinção entre ambos. Com o tempo tais distinções tendem a ser irreais, entretanto sobrevivem por tradição. Onde a força de trabalho é mais enfraquecida e esgotada, o trabalho simples relaciona-se àquele que despende força muscular e é embrutecido.

${ }^{8}$ Os indicadores do DIEESE (2016, p. 3) demonstram que "as ocupações mais protegidas são as mais afetadas: estima-se a redução de 1,9 milhão de empregos formais, com registro em carteira de trabalho, e o decréscimo de 765 mil postos sem carteira de trabalho assinada [...] Em contrapartida, houve aumento das ocupações menos protegidas pela legislação, como o trabalho por conta própria (ampliação de 1,4 milhão de ocupados) e do trabalho doméstico (240 mil). Por outro lado, o número dos que atuam como trabalhador familiar auxiliar, ocupação também pouco protegida, teve queda de 411 mil pessoas no período".

\section{Referências}

ALGEBAILE, Eveline. A formação dos trabalhadores na escola: onde está o centro da disputa? Trabalho Necessário, Rio de Janeiro, ano 14, n. 25, p. 53-69, 2016.

ALVES, Giovanni. Trabalho e subjetividade: o espírito do toyotismo na era do capitalismo compulsório. São Paulo, SP: Boitempo, 2012.

CORDEIRO, Denise. Juventude nas sombras: escola, trabalho e moradia em territórios de precariedades. Rio de Janeiro: Lamparina, FAPERJ, 2009.

DIEESE. Departamento Intersindical de Estatística e Estudos Socioeconômicos. Emprego em Pauta, São Paulo, Boletim n. 0, maio 2016.

FORACCHI, Maria Alice. O estudante e a transformação da sociedade brasileira. 2. ed. São Paulo: Companhia Editora Nacional, 1977. 
GENTILI, Pablo. Educar para o desemprego: a desintegração da promessa integradora. In: FRIGOTTO, Gaudêncio (Org.). Educação e Crise do Trabalho: perspectivas de final de século. 3. ed. Petrópolis: Vozes, 1999. p. 76-99.

IBGE. Instituto Brasileiro de Geografia e Estatística. Pesquisa Nacional por Amostra de Domicílio 2009. Brasília, DF: IBGE, 2009. Disponível em: <www.ibge.gov.br>. Acesso em: 10 fev. 2016. (identificação retirada por anonimato). Relatório de Pesquisa (2017).

INEP. Instituto Educacional de Estudos e Pesquisas Educacionais Anísio Teixeira. Censo Escolar 2016: notas estatísticas. Brasília: MEC, fevereiro 2017.

MARCASSA, Luciana Pedrosa. (Coord.). Juventude pobre e escolarização: relações com a escola, o trabalho e a cultura em territórios de precariedade. Relatório de Pesquisa. Departamento de Metodologia de Ensino, Centro de Ciências da Educação, Universidade Federal de Santa Catarina, 2017. (mimeo).

MARX, Karl. O capital: crítica da economia política. 25. ed. Rio de Janeiro: Civilização Brasileira, 2008, livro I, vol. 1, p. 211-231.

NOGARA JUNIOR, Gilberto. O Programa Ensino Médio Inovador (PROEMI) no contexto das políticas do Banco Mundial (BM): rumo à formação de trabalhadores de novo tipo? 2015. 210f. Dissertação (Mestrado em Educação) - Universidade Federal de Santa Catarina, Centro de Ciências da Educação, Programa de Pós-Graduação em Educação, Florianópolis, 2015.

OLIVEIRA, Francisco. A economia brasileira: crítica à razão dualista. 6. ed. Petrópolis, RJ: Vozes, 1988.

RUMMERT, Sonia Maria; ALGEBAILE, Eveline; VENTURA, Jaqueline. Educação e formação humana no cenário da integração subalterna no capital imperialismo. In: SILVA, Mariléia Maria da; EVANGELISTA, Olinda; QUARTIERO, Elisa Maria (Orgs.). Jovens, trabalho e educação: a conexão subalterna de formação para o capital. Campinas: Mercado das Letras, 2012. p. 15-70.

SANTOS, Milton. Por uma outra globalização: do pensamento único à consciência universal. 20. ed. Rio de Janeiro/São Paulo: Record, 2011.

SPÓSITO, Marília Pontes. (Des)encontros entre os jovens e a escola. In: FRIGOTTO, Gaudêncio; CIAVATTA, Maria (Orgs.). Ensino Médio: ciência, cultura e trabalho. Brasília: MEC/SEMTEC, 2004, p. 73-91.

VENDRAMINI, Célia Regina; MARCASSA, Luciana Pedrosa; TITTON, Mauro; CONDE, Soraya Franzoni. Escola, trabalho e perspectiva de futuro de jovens estudantes. RIAEE - Revista IberoAmericana de Estudos em Educação, Araraquara, v.12, n.4, p.2155-2176, out/dez, 2017. 
Youth, work and school in precarious territories

\begin{abstract}
This article discusses the relationship between youth, work and school based on research data on youth and schooling developed between 2014 and 2016 in 10 public schools located in the Morro da Cruz massif (Florianópolis, SC), a geopolitically segregated and peripheral region, located in the center of the city. Data are collected through bibliographic studies, document analysis, application of questionnaires and focus groups. The analyzes produced so far show that the work is central to the life of the young people researched as much to strengthen the relation with the school, considering the professional and life projections, as for dialectically competing with time of studies outside the school space.
\end{abstract}

Keywords: Youth. Work. School, Morro da Cruz Massif.

Luciana Pedrosa Marcassa

E-mail: lumarcassa@gmail.com

Soraya Franzoni

E-mail: sorayafconde@gmail.com
Juventud, trabajo y escuela em territorios de precaridad

\section{Resumem}

Este artículo aborda la relación entre los jóvenes, el trabajo y la escuela a partir de datos de una encuesta sobre juventud y escolarización desarrollada entre 2014 y 2016, en 10 escuelas públicas ubicadas en el macizo del Morro da Cruz (Florianópolis, SC), región geopolítica segregada y periférica, aunque situada en el centro de la ciudad. Los datos ha recogido mediante estudios bibliográficos, análisis de documentos, aplicación de cuestionarios y grupos focales. Los análisis producidos hasta ahora evidencian que el trabajo es central en la vida de los jóvenes investigados tanto por fortalecer la relación con la escuela, teniendo en vista las proyecciones profesionales y de vida, como por dialécticamente, competir con tiempo de estudios fuera del espacio escolar y ser un elemento determinante de la fragilidad y el alejamiento de los estudios.

Palabras clave: Juventud. Trabajo. Escuela. Maciço del Morro de la Cruz.

Enviado em: 16/05/2017

Versão Final Enviada em: 29/05/2017

Aprovado em: 02/06/2017 